\title{
Genital Chlamydia trachomatis infections
}

\section{Maria Agnese Latino', Daniela De Maria', Andrea Caneparo', Claudia Rosso', Gianfranco De Intinis', Anna Maria Cali' ${ }^{2}$, Pierangelo Clerici ${ }^{2}$, Marco Cusini ${ }^{2}$, Ivano Dal Conte ${ }^{2}$, Tiziano Maggino², Enrico Magliano², Alfonso Panuccio², Roberto Pozzoli², Mario Rassu², Barbara Suligoi ${ }^{2}$, Riccardo Terramocci ${ }^{2}$}

'S. S. Dip. di Batteriologia, Az. Osp. O.I.R.M. - Sant'Anna - Torino

${ }^{2}$ Gruppo di Lavoro AMCLI per le Infezioni Sessualmente Trasmesse (GLIST- coordinatore Latino M.A.)

Key word: Chlamydia trachomatis, epidemiology, risk factors, diagnosis

\section{Infezioni genitali da Chlamydia trachomatis}

\section{SUMMARY}

Chlamydia trachomatis (C.t.) infection is one of the most prevalent sexually transmitted disease in Europe and in developed countries.

The main biological features and pathogenic mechanisms of C.t. infection are summarized in this review. It usually occurs without symptoms and often goes undiagnosed. If untreated, it can cause severe consequences for women, including pelvic inflammatory disease (PID), ectopic pregnancy and tubal infertility. Several studies have found that Chlamydia is more common among young women $<25$ years old, with multiple sexual partners within six months and non protected intercourses. Because re-infection rates are high, complications may be reduced if partners are treated and women re-tested. This paper emphasizes the importance of counselling and prevention programs and underlines that selective screening of high-risk population remains an essential component of C.t. control. In the last years, the detection of C.t. infection has been improved in sensitivity and specificity. We describe the main diagnostic techniques, from culture, enzyme immunoassay (EIA), direct fluorescent-antibody assay (DFA) to the new DNA-based test systems.

Actually, NAATs (nucleic acid amplification tests) are regarded as the gold standard diagnostic techniques for chlamydial infections.

Received June 19, 2007

Accepted July I, 2007

\section{BiOLOGIA}

Chlamydia trachomatis (C.t.) è un parassita endocellulare obbligato che appartiene alla famiglia delle Chlamydiaceae comprendente due generi, Chlamydia e Chlamydophila, e nove specie. Di queste solo tre sono responsabili di infezioni nell'uomo: C. trachomatis, appartenente al genere Chlamydia e C. pneumoniae e C. psittaci appartenenti al genere Chlamydophila (10).

Mentre le infezioni da C. pneumoniae e C. psitta$c i$ interessano prevalentemente l'apparato respiratorio, C.t. ha un particolare tropismo per l'epitelio genitale e congiuntivale.

Sulla base delle differenze antigeniche, sono stati identificati diciannove serovars di C.t.: i serovars $\mathrm{A}, \mathrm{B}, \mathrm{Ba}$ e $\mathrm{C}$ sono responsabili di patologie a carico dell'occhio e sono associati al tracoma endemico, i serovars D, Da, E, F, G, Ga, H, I, Ia e K sono più comunemente associati ad infezioni del tratto genitale a trasmissione sessuale, alle congiuntiviti da inclusi o alle polmoniti neonatali, infine i serovars L1, L2, L2a e L3 sono associati al linfogranuloma venereo (14).

Tabella I. Serovars di Chlamydia trachomatis

\begin{tabular}{l|l|l|l|}
\hline Specie & Serovar & Sesso & Patologia \\
\hline
\end{tabular}

\begin{tabular}{|c|c|c|c|}
\hline \multirow{3}{*}{ 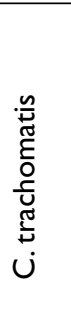 } & $\mathrm{Da} A$ a $C$ & 2 sessi & $\begin{array}{l}\text { Tracoma, Congiuntivite, } \\
\text { Cheratite }\end{array}$ \\
\hline & $\mathrm{Da} D$ a $K$ & \begin{tabular}{|l|} 
Donna \\
Uomo \\
2 sessi \\
Neonato
\end{tabular} & $\begin{array}{l}\text { Cervicite, Uretrite, } \\
\text { Endometrite, MIP, Periepatite } \\
\text { Uretrite, Epididimite } \\
\text { Congiuntivite, Artrite reattiva } \\
\text { (Sindrome di Reiter), Proctite } \\
\text { Oftalmia, Pneumopatia }\end{array}$ \\
\hline & \begin{tabular}{|l|} 
LI L2 L3 \\
\end{tabular} & 2 sessi & Linfogranuloma venereo \\
\hline
\end{tabular}

Il parassitismo endocellulare obbligato è spiegato dal fatto che C.t., incapace di sintetizzare ATP, deve necessariamente utilizzare quello della cellula ospite.

Il ciclo vitale di Chlamydia è di tipo dimorfico. La forma infettante è rappresentata dal corpo elementare $(\mathrm{CE})$, di aspetto rotondeggiante e uniformemente denso al microscopio elettronico, in grado

\section{Corresponding author: Maria Agnese Latino}

S.S. Dip. Batteriologia - Az. Osp. O.I.R.M. - Sant'Anna - C.so Spezia, 60 - 10126 Torino

Tel.: 0II 3I345624 - Fax:0II 663868I - E-mail:maglat@hotmail.com 
di sopravvivere in ambiente extracellulare e di aderire alla membrana citoplasmatica grazie alle sue proteine di membrana quali la MOMP (Major Outer Membrane Protein) e le POMPs (Polymorphic Membrane Protein). I determinanti antigenici della MOMP definiscono i serovars e sembrerebbe che alcuni di questi $(\mathrm{H}, \mathrm{I}, \mathrm{J}, \mathrm{K})$ siano responsabili di infezioni più frequentemente croniche o persistenti (26).

Penetrato per endocitosi all'interno della cellula, il CE subisce un processo di idratazione che conduce alla trasformazione in corpo reticolare (CR), metabolicamente attivo e capace di scissione binaria. Dopo un certo numero di divisioni, le particelle accumulate nel vacuolo fagosomiale costituiscono una vera e propria colonia evidentemente come un'inclusione citoplasmatica caratteristica che si colora in bruno con soluzione iodo-iodurata di Lugol per la presenza di una matrice glicogenica (14).

Alla scissione segue un processo di disidratazione che prelude alla formazione di nuovi $\mathrm{CE}$ che, in seguito alla morte della cellula e alla rottura del fagosoma, diffondono infettando altre cellule (14, $26,106)$. Per potersi moltiplicare il microrganismo ha sviluppato delle particolari capacità: l'inibizione fagolisosomiale ed il controllo dell'attività apoptosica della cellula. C.t. invia dei segnali anti apoptosi all'inizio del ciclo e dei segnali pro apoptosi alla fine per facilitare la fuoriuscita dei CE neoformati (26).

Oltre ai CE e ai CR sono stati messi in evidenza, sia in vitro sia in vivo, i cosiddetti "corpi aberranti" che rappresentano una forma di latenza, non coltivabile, e sarebbero responsabili della persistenza e della cronicità dell'infezione. I corpi aberranti, da 10 a 100 volte più grandi dei $\mathrm{CR}$, sono sprovvisti di MOMP e producono in gran quantità proteine di stress come la Chsp 60 (heat shock protein specifica di Chlamydia) (51). È stato visto che una prolungata o ripetuta esposizione alla Chsp 60 , come accade durante una infezione persistente, può portare alla produzione di anticorpi diretti sia verso la hsp 60 di C.t. sia verso quella di origine umana, provocando quindi una risposta di tipo autoimmune che, a sua volta giocherebbe un ruolo importante nella cronicizzazione dell'infezione. Il meccanismo patogenetico è legato quindi non solo alle caratteristiche di virulenza del microrganismo, ma anche alla risposta immune dell'organismo, particolarmente intensa, che nel caso di infezioni latenti o croniche, porta ad un processo fibrotico-cicatriziale con conseguente danno tissutale. C.t. è infatti un forte immunogeno che stimola sia la risposta umorale sia quella cellulo-mediata e l'outcome dell'infezione dipende dall'interazione delle varie citochine secrete dai linfociti atti- vati (IFN- $\gamma$, TNF- $\alpha$, IL-10 etc.). L'infiltrato infiammatorio, ricco in linfociti $\mathrm{T}$ e $\mathrm{B}$, si caratterizza, in fase precoce, per la neoformazione locale di follicoli dotati di centri germinativi. Più tardivamente prevalgono manifestazioni fibrotiche con presenza di un infiltrato costituito prevalentemente da linfociti $\mathrm{T}$ e cellule di tipo monocito-macrofagico. Successive reinfezioni costituiscono un forte stimolo alla fibrogenesi. L'impossibilità del sistema immune dell'organismo di eliminare efficacemente il microrganismo scatena meccanismi di contenimento dell'infezione che si traducono in uno stato di infiammazione cronica con conseguenti gravi impedimenti funzionali (26).

\section{EPIDEMIOLOGIA}

L'infezione da C.t. rappresenta una delle infezioni batteriche, sessualmente trasmesse più diffusa in tutti i paesi industrializzati anche se la prevalenza nella popolazione generale resta difficile da valutare perché i dati sono spesso parcellizzati e difficilmente sovrapponibili.

L'Organizzazione Mondiale della Sanità stima che ogni anno nel mondo vi siano almeno 92 milioni di nuovi casi di infezione. Nel 2001, l'infezione genitale da Chlamydia è risultata negli Stati Uniti la malattia infettiva più comunemente denunciata con una stima annuale di 4 milioni di nuovi casi ed un costo sociale di 2.4 miliardi di dollari l'anno. Per l'Europa le stime sarebbero di 5 milioni di nuovi casi annui con una prevalenza del 3-6\% nella popolazione adulta $(115,129)$.

Alla fine degli anni ' 80 , in seguito alla diffusione di programmi di screening, in alcuni paesi come la Svezia, si è assistito ad un notevole decremento della prevalenza dell'infezione, decremento che si è però arrestato intorno alla metà degli anni ' 90 ed al quale ha fatto seguito un considerevole aumento segnalato in molti paesi europei (37).

L'età inferiore ai 25 anni e il sesso femminile rappresentano i maggiori fattori di rischio (107). Uno dei motivi per cui le giovani donne sono particolarmente vulnerabili è dato dal fatto che C.t. predilige un ambiente alcalino ed ha una particolare affinità per l'epitelio colonnare; durante l'adolescenza il pH vaginale è infatti relativamente alcalino e l'epitelio colonnare è maggiormente esposto (ectropion) (52). Secondo i dati della letteratura americana le ragazze di età compresa tra i 13 e i 19 anni costituiscono il gruppo sociale a più alto rischio di acquisire l'infezione. Si stima che la prevalenza nelle teenagers superi di $1-5 \%$ la percentuale di infezione nelle donne adulte (115).

Si stima che oltre il $70 \%$ delle infezioni sono diagnosticate in donne d'età compresa tra i 15 e i 24 anni $(29,71)$.

Per quanto riguarda la prevalenza in Europa, una 
revisione sistematica di 90 studi condotta nel Regno Unito da Adams et al nel 2004 (2), rileva che le principali variabili che influenzano la prevalenza sono l'età ed il luogo di reclutamento della popolazione. Questa ampia review evidenzia, infatti, una prevalenza dell' $8.1 \%$ nelle donne al di sotto dei 20 anni, del 5.2\% in quelle con età compresa tra i 20 ed i 24 e dell' $1.4 \%$ nelle donne di oltre 30 anni. Valori crescenti nella fascia d'età minore di 20 anni sono stati osservati in popolazioni selezionate in diversi contesti assistenziali: $8.6 \%$ nella popolazione proveniente dagli ambulatori dei medici di base, $10 \%$ in quella afferente ai consultori familiari, $13.6 \%$ nelle donne afferenti agli ambulatori per l'interruzione di gravidanza, $17.3 \%$ negli ambulatori di medicina genito-urinaria.

Questi dati possono aiutare a capire l'efficacia dei provvedimenti di screening basati sul coinvolgimento dei consultori e dei medici di base, primo punto di contatto col sistema sanitario per la maggior parte della popolazione $(70 \%$ degli uomini e $90 \%$ delle donne con età $<35$ anni, in Gran Bretagna).

Negli uomini la maggiore prevalenza è segnalata nelle fascia di età compresa tra i 20 ed i 29 anni (65). Altri fattori che influenzano i dati di prevalenza sono legati all'attività sessuale (partners multipli e/o nuovi negli ultimi mesi), alla presenza di infezione nel partner, allo stato di single, all'uso non costante o inadeguato dei metodi contraccettivi di barriera, a pregresse o coesistenti infezioni sessualmente trasmesse, all'etnia, alla scolarità, al livello di urbanizzazione $(44,116,119)$.

Ad esempio, Verhoeven et al. (120) riportano una prevalenza di infezioni del $2.4 \%$ delle donne che hanno avuto un solo partner nell'ultimo anno, dell' $8.6 \%$ di quelle che hanno avuto 2 partners e del $17.9 \%$ per quelle che hanno avuto 6 o più partners. Gli stessi Autori evidenziano una prevalenza del $20.5 \%$ nelle donne il cui partner presentava dei sintomi di uretrite contro il $4.4 \%$ nelle donne con partner asintomatico.

Veldhuijzen 2005 et al. (119), in uno studio, condotto in Olanda, per identificare i fattori di rischio, oltre alla giovane età, correlati all'infezione, riporta un aumento della prevalenza $(12.5 \%$ versus $4.2 \%$ ) in chi ha avuto almeno un nuovo partner nei due mesi precedenti il test.

In molti lavori l'uso del condom è associato ad una riduzione del rischio di infezione variabile dal 10 al $90 \%$, altri studi indicano, al contrario, che non vi è differenza di prevalenza statisticamente significativa tra l'uso o il non uso. Questo dato può essere spiegato dal fatto che esiste una diffusa disinformazione riguardante il corretto uso del preservativo soprattutto nei giovani: la dichiarazione di "usare sempre" il condom non sempre coincide con usarlo "il $100 \%$ delle volte" e soprattutto non coincide con usarlo correttamente fin dall'inizio e/o comunque per tutta la durata del rapporto sessuale $(45,124)$.

Una maggiore prevalenza dell'infezione è stata inoltre osservata nei centri urbani rispetto alle zone rurali $(44,116,119)$ e nei soggetti che non hanno una relazione stabile rispetto i coniugati/conviventi (76). Per quanto riguarda l'etnia, l'infezione da C.t. sembra essere più diffusa tra gli individui di razza nera o ispanica (79) e tra quelli provenienti dai paesi caraibici $(44,65)$.

Dati europei mostrano un significativo aumento dell'infezione nei paesi dell'Europa Orientale. Uno studio ucraino (74) riporta un incremento dei tassi di notifica di infezione di 2.4 volte tra il 1995 e il 2000 con un passaggio da 16.1 casi a 54.2 casi per 100.000 abitanti. Nella Repubblica Ceca (77) vengono riportati valori di prevalenza del 19.5\% (27.6\% negli adolescenti) ed in Slovenia (61) del 6-16.5\% tra le donne asintomatiche.

In Italia l'associazione tra l'infezione da C.t. e la provenienza dai Paesi dell'Europa dell'Est è confermata dal lavoro di Matteelli et al. (73) condotto su un gruppo di prostitute, in cui l'unico fattore di rischio significativamente associato con l'infezione è la provenienza dai paesi dell'Europa dell'Est.

Un recente studio (66) realizzato in Piemonte su 1180 giovani donne di età compresa tra i 18 e i 24 anni ha evidenziato una prevalenza globale dell' $10.4 \%$. I fattori di rischio individuati sono stati: l'età del primo rapporto sessuale inferiore ai 16 anni (OR $2[1.1 ; 3.6]$ ), non avere un partner stabile (OR $2.8[1.8 ; 4.3])$, l'aver avuto uno o più partners occasionali o più di un partner negli ultimi 6 mesi (OR $3.2[2.1 ; 4.8]$ ), la presenza di una sintomatologia genitale nel partner (OR 3 [1.9; 4.5]) e la provenienza da paesi dell'Est europeo o del Sud America (OR 2.1 [1.3; 3.6]).

La prevalenza tra donne gravide, secondo l'Organizzazione Mondiale della Sanità, negli anni ' 90 era del $2.7 \%$ in Italia, del $3.9 \%$ in Francia, del $4.9 \%$ in Olanda, del $5.4 \%$ in Ungheria, del $6.7 \%$ in Danimarca e dell' $8 \%$ in Islanda: è quindi sovrapponibile a quella della popolazione generale ed è associata agli stessi fattori di rischio (129).

\section{Trasmissione dell'infezione}

Il rischio di trasmissione dell'infezione da C.t. in seguito ad un rapporto sessuale non protetto con un partner infetto è praticamente sconosciuto (84). Il tasso di coinfezione calcolato, in uno studio tedesco (20), su una popolazione di 1690 coppie con prevalenza dell'infezione del $4.6 \%$ è stato del $35 \%$ dei casi. Nel 19\% dei casi solo il partner femminile era infetto e solo quello maschile nel $46 \%$. La durata della relazione sembrerebbe non influenzare il tasso di trasmissione. In un altro 
studio americano (97), la concordanza di infezione è stata rilevata nel $53 \%$ delle coppie. Nell'insieme questi lavori evidenziano un tasso di trasmissione bi-direzionale di $C$. $t$. relativamente alto, in particolare nelle coppie più giovani.

Per quanto riguarda la trasmissione verticale esistono pochi studi ben disegnati e sufficientemente ampi sulla stima del rischio di trasmissione di C.t. dalla madre al neonato $(7,42,130)$. I dati della letteratura indicano che il tasso di trasmissione si attesta sull'ordine del $40-60 \%$ e che il parto cesareo può ridurne il rischio.

\section{I programmi di screening}

Strategie di prevenzione delle infezioni genitali da C.t. possono essere applicate sia prima o durante lo sviluppo dell'infezione stessa sia dopo la terapia. La prevenzione primaria ha lo scopo di evitare il contagio, quella secondaria mira alla diagnosi precoce dell'infezione in modo da evitare la diffusione e ridurne la durata, mentre la terziaria cerca di prevenire le complicanze e le recidive. I programmi di screening costituiscono un elemento essenziale nell'ambito della prevenzione secondaria.

L'efficacia dello screening può essere valutata con la diminuzione dell'incidenza o della prevalenza dell'infezione e delle sue complicanze ed è quindi importante che il tasso di adesione sia elevato. Un programma di screening è considerato economicamente valido quando gli obiettivi sono raggiunti con un costo inferiore a quello della terapia delle sequele. Diversi paesi come gli Stati Uniti (12), il Canada, l'Australia, la Svezia (49), l'Olanda, la Danimarca (68) e la Gran Bretagna (65) hanno già avviato o stanno avviando programmi di screening selettivi basati sulla valutazione di uno o più fattori di rischio. Tra questi, l'età inferiore ai 25 anni per le donne è quello preso in considerazione da tutti (92). Altri lavori hanno ancora dimostrato che, utilizzando come criterio di selezione la giovane età in combinazione con una o due altre variabili come l'etnia, lo stato civile, la presenza di sintomi, si potrebbe diagnosticare $1^{\prime} 85-95 \%$ delle infezioni $(38,48,87)$. Negli ultimi anni l'introduzione di tecniche diagnostiche basate sull'amplificazione degli acidi nucleici (NAATs) ha permesso di utilizzare, per la diagnosi delle infezioni da C.t., campioni alternativi, rispetto al tampone endocervicale o uretrale, come le urine o i tamponi vaginali e vulvari. L'utilizzo di questi campioni, facilmente ottenibili anche senza il ricorso a strutture sanitarie, ha portato all'introduzione di nuovi modelli di screening, basati sulla raccolta del campione a domicilio.

Un'indagine condotta da Tebb et al. (111) ha valutato le preferenze delle adolescenti rispetto al tipo di prelievo: prelievo di urine a domicilio, in ambulatorio, tampone vaginale, tampone cervicale ese- guito da un medico. La maggioranza delle ragazze ha indicato il prelievo di urine a domicilio come metodo di prima scelta (52\%) seguito dalla raccolta di urine presso l'ambulatorio e dal tampone vaginale. Il prelievo cervicale è stato indicato dal $60 \%$ delle ragazze come metodo di ultima scelta. Un altro studio realizzato da Østergaard et al. (89) ha confrontato l'adesione e la ricaduta di due programmi di screening, il primo basato sul prelievo a domicilio ed il secondo sul prelievo eseguito presso uno studio medico. L'adesione al primo programma è stata molto maggiore rispetto al gruppo indirizzato allo screening tradizionale ( $93 \%$ vs $7.6 \%)$, con un conseguente e significativo vantaggio in termini di riduzione della prevalenza di infezione ad un anno (2.6\% vs $6.6 \%)$ e di riduzione dei casi di MIP trattati.

\section{Efficacia e costi}

Negli Stati Uniti i dati del CDC hanno evidenziato una netta associazione tra i programmi di screening e la diminuzione della prevalenza delle infezioni da C.t. che, nelle donne afferenti ai consultori familiari, scendeva dal 9.3\% nel 1988 al 3.3\% nel 1995 (11). In Svezia, negli anni seguenti l'introduzione dello screening, la prevalenza è passata dal $10.7 \%$ nel 1985 al 3.2\% nel 1993 nelle donne e dal $18.3 \%$ al $7.1 \%$ negli uomini (49) e nello stesso periodo è stata osservata anche una diminuzione dei casi di MIP e di GEU $(33,59)$.

Altri lavori hanno inoltre dimostrato che l'efficacia dei programmi di screening è direttamente proporzionale alla loro durata. In Olanda ad esempio in 10 anni la prevalenza delle infezioni da C.t. nelle donne di età compresa tra i 15 e 124 anni, è passata dal $6.3 \%$, prima dello screening, al $2.1 \%$ con un calo quindi, del $67 \%$ (127).

Uno studio revisionale condotto da Honey et al. (53) in cui gli outcome selezionati sono stati i casi di infezione diagnosticati, i casi di MIP pervenuti e i costi associati, ha dimostrato che lo screening è conveniente ed efficace con una prevalenza compresa tra $3.1 \%$ e $10 \%$ usando l'età come variabile di selezione e usando test di amplificazione di acidi nucleici su campioni di urina.

Un altro recente lavoro (56) dimostra che lo screening annuale in donne di età compresa tra 15 e 29 anni in concomitanza con uno screening ogni 6 mesi nei soggetti con storia di infezione risulta la strategia dal migliore rapporto costo-efficacia. Implementare uno screening annuale modificato e ristretto alla fascia di età 15-24 anni risulta vantaggioso in caso di forti restrizioni di budget.

\section{L'adesione}

Dalla maggior parte dei lavori, come dal rapporto pubblicato dal CDC alla fine del 2004 (49), emer- 
ge che comunque l'adesione ai programmi di screening resta ancora bassa. Ciò può essere imputato a diversi fattori individuabili sia a livello di sistema, sia di erogazione del servizio sia di problematiche inerenti al paziente.

\section{Fattori dipendenti dal sistema:}

1. carenza nella disponibilità di metodi non invasivi (urine o prelievo vaginale). Tale disponibilità eliminerebbe la necessità della visita ginecologica non sempre ben accetta.

2. insufficienti sistemi di feedback e promemoria per lo screening

\section{Fattori legati all'erogazione del servizio:}

1. non consapevolezza da parte degli operatori sanitari dell'elevata prevalenza di C.t. nelle adolescenti e nelle giovani donne

2. non pensare che le adolescenti siano sessualmente attive

3. disagio o mancanza di tempo per accertare eventuali fattori di rischio e offrire lo screening

4. disinformazione circa la disponibilità di test non invasivi

\section{Fattori correlati ai pazienti:}

1. stigma associato alle infezioni sessualmente trasmesse

2. non consapevolezza dell'elevata prevalenza, della natura asintomatica e delle serie complicanze correlate all'infezione da C.t.

3. presenza dei genitori durante la visita delle adolescenti che preclude una valutazione del rischio sessuale

4. paura della non riservatezza delle informazioni

Le donne accettano lo screening se riescono a capire che l'infezione da C.t. rappresenta un problema da non sottovalutare, che si tratta di un'infezione comune, spesso asintomatica e che può compromettere la fertilità $(4,9,16,24,84,95,99)$. Altri fattori che influiscono sull'adesione, sono la presenza di un partner nuovo o sintomatico, la gravidanza $(4,15,84,95)$ e non da ultimo la gratuità.

\section{Partner notification}

L'informazione, il controllo e la terapia del partner rientrano nel programma di screening. La necessità di limitare il rischio di reinfezione implica rintracciare sistematicamente il o i partner e la loro presa in carico diagnostica e terapeutica. Tutti i pazienti con un test positivo devono essere esortati ad informare i loro partner ed a convincerli della necessità di eseguire il test e/o di essere trattati.

\section{ASPETTI CLINICI}

L'infezione colpisce prevalentemente le giovani donne di età inferiore ai 25 anni ed i sintomi generalmente lievi, aspecifici o addirittura inesistenti (il $70-80 \%$ delle infezioni nella donna ed il $25-$ $50 \%$ nell'uomo decorre in modo asintomatico) (44, 116) comportano, sovente, una sottostima della diffusione dell'infezione e quindi una maggiore facilità della trasmissione.

\section{Nella donna \\ Cervico-vaginite}

C.t. è responsabile di una cervicite muco-purulenta a carico delle cellule squamo-colonnari. Il sito iniziale dell'infezione è la cervice ma possono essere coinvolte anche l'uretra e il retto.

L'asintomaticità, quale caratteristica prevalente, si alterna a casi in cui l'infezione si manifesta principalmente con leucorrea, ma anche con spotting o sanguinamenti post-coitali ed edema nell'area di ectopia. La sintomatologia è comunque banale nella maggior parte dei casi e passa spesso inosservata. All'osservazione colposcopica la cervice può presentare ectopia ed edema, con sanguinamento in seguito a delicato tamponamento endocervicale (91).

\section{Malattia Infiammatoria Pelvica (MIP)}

Se non adeguatamente trattata, l'infezione cervico-vaginale può risalire verso l'apparato genitale alto e condurre, nel $25 \%$ dei casi circa, ad una MIP con interessamento dell'endometrio, delle salpingi e di altre formazioni annessiali $(32,91)$. L'infezione intrauterina può essere primitiva (per trasmissione sessuale), secondaria a procedure invasive (dilatazione e curettage, interruzione di gravidanza, inserimento di un dispositivo intrauterino o esecuzione di una isterosalpingografia) o può essere successiva al parto.

Le MIP acute si presentano sotto numerosi aspetti clinici che vanno dall'endometrite asintomatica alla salpingite severa, piosalpinge, ascesso tubo-ovarico etc. L'infezione si può estendere oltre il tratto riproduttivo e causare una peritonite pelvica circoscritta, una peritonite generalizzata o una periepatite (91). Nella MIP acuta il dolore é praticamente costante ma spesso unilaterale e associato a metrorragia e può dunque evocare un'altra diagnosi. Si possono avere febbre, VES notevolmente aumentata, disuria e pollachiuria coesistendo una uretrite o una cistite. La massima incidenza si ha al di sotto dei 20 anni con circa il $60 \%$, dei casi, seguita da un decremento graduale fino al $15 \%$ dopo i 40 anni. Le MIP acute rappresentano solo la punta dell'iceberg delle infezioni del tratto genitale alto: sempre più si evidenziano casi atipici o silenti che rendono difficile la diagnosi. Studi sieroepidemiologici hanno supportato il concetto delle MIP silenti mostrando lo stretto legame tra presenza di 
anticorpi sierici anti C.t. e fattore tubarico di infertilità o gravidanze ectopiche in pazienti anche senza segni di MIP (91).

Il dolore può essere vago o presentarsi sotto forma di dispareunia o di dolore ai quadranti addominali inferiori. La dolorabilità alla mobilizzazione della cervice, alla palpazione degli annessi o dell'addome può essere del tutto assente. In questi casi la laparoscopia é indispensabile per la diagnosi e la ricerca degli anticorpi dovrebbe essere eseguita sistematicamente. Un loro aumento é riscontrato anche quando la ricerca diretta di C.t. risulta negativa. Sembra esistere una correlazione tra l'aumento del tasso di anticorpi e la gravità delle lesioni. In uno studio caso-controllo (108) che ha preso in esame i fattori di rischio associati a MIP all'interno di una popolazione di adolescenti, la presenza di infezione da C.t. è stato il singolo, maggior fattore di rischio.

È stato inoltre dimostrato che la terapia dell'infezione anche asintomatica, da C.t. riduce il rischio di sviluppare un MIP (22) e che, laddove c'è stata una riduzione nella prevalenza delle infezioni di C.t., grazie alle politiche di screening, come in Svezia, è stato osservato un declino nel numero annuale di donne ospedalizzate per MIP (89).

\section{Infertilità tubarica e gravidanze extra-uterine ( $G E U)$}

Una MIP, non trattata, può causare, a sua volta, lo sviluppo di lesioni cicatriziali ed aderenze pelviche con algie pelviche croniche. Dal momento che C.t. invade peculiarmente l'epitelio colonnare, il segmento ampollare ciliato delle tube di Fallopio risulta particolarmente sensibile all'infezione. Le lesioni cicatriziali sono all'origine dell'occlusione tubarica con conseguente sterilità e un aumentato rischio di GEU. Tuttavia non tutte le donne con un'infezione genitale da C.t. sviluppano una patologia tubarica. Solo un'infiammazione cronica, come avviene in seguito ad infezioni persistenti o ricorrenti, può indurre una reazione di ipersensibilità ritardata con conseguente danno tubarico.

Dopo un singolo episodio di MIP il rischio relativo di infertilità da danno tubarico è circa il $10 \%$ e aumenta ad ogni episodio ripetuto (128). L'infezione da C.t. sembra essere responsabile di circa il $40 \%$ delle GEU mentre il $60 \%$ delle donne con infertilità tubarica presenta evidenza sierologica di pregressa infezione da C.t. (53). Anticorpi anti-Chlamydia sono stati trovati nell' $80 \%$ di donne infertili con danno tubarico e nel $40 \%$ di donne infertili con tube non danneggiate $(94,105)$. Studi sieroepidemiologici hanno dimostrato una stretta correlazione tra presenza di anticorpi antiC.t. e infertilità tubarica o GEU indipendentemente dal fatto che le donne riferissero o meno un epi- sodio di MIP, ciò a conferma del fatto che la maggior parte delle infezioni tubariche da C.t. resta silente o comunque sub-clinica e quindi non trattata (105). In particolare la presenza di anticorpi anti Chsp 60 è strettamente associata con l'occlusione tubarica e conferma il ruolo di questa proteina nella sua patogenesi $(6,28,113)$.

La GEU, definita come l'impianto della blastocisti in un sito diverso dalla cavità uterina, rappresenta il $9 \%$ delle cause di mortalità materna e ne sarebbe, se non trattata, la prima causa nel primo trimestre di gravidanza. Le implicazioni della gravidanza extrauterina per la fertilità futura sono significative: in seguito ad una GEU nel 10-20\% dei casi si avranno gravidanze extrauterine ricorrenti e solo un terzo delle donne riuscirà a partorire un neonato vivo. Eziologicamente è stata correlata con l'incremento dell'incidenza della MIP. Altre cause sono l'uso di IUD e l'aumento delle procedure chirurgiche per il trattamento delle patologie tubariche (6).

Oltre un terzo delle donne con pregressa MIP sviluppa algie pelviche croniche ed il rischio raddoppia o triplica in seguito a due o più episodi o in caso di infezione persistente (46).

\section{Sindrome di Fitz, Hugh Curtis (FHCS)}

Si tratta di una periepatite, caratterizzata da dolore ai quadranti addominali superiori e dolorabilità alla palpazione che si sviluppa nel 3-10\% delle donne affette da MIP acuta. Ė stata descritta per la prima volta nel 1930 dal ginecologo Curtis, che riportò aderenze a "corda di violino" tra la faccia anteriore del fegato e la parete addominale anteriore in associazione a salpingiti gonococciche. Nel 1934 Fitz-Hugh descrisse tre casi di epatite o periepatite nel quadrante addominale superiore, ancora associati a salpingiti gonococciche. Per anni considerata una sequela delle salpingiti gonococciche, oggi la maggior parte dei casi è da attribuire ad una infezione da C.t. I sintomi insorgono durante o dopo una MIP. In circa il 5\% dei casi di salpingite acuta una laparoscopia, eseguita precocemente, rivela un'infiammazione periepatica che varia dall'edema ed eritema della capsula epatica all'essudato con aderenze tra il peritoneo viscerale e parietale $(86,109)$. La FHSC può presentarsi in forma acuta, caratterizzata da infiammazione essudativa della capsula epatica, congestione capsulare, emorragia, $\mathrm{o}$ in forma cronica caratterizzata da aderenze fibrose tra la superficie anteriore del fegato e la parete addominale, con il tipico aspetto a "corde di violino". Recenti studi indicano che, nel 30\% dei casi, una FHSC può insorgere indipendentemente dall'instaurarsi di una salpingite (62).

\section{Cancro della cervice uterina}

Diversi studi epidemiologici ipotizzano che l'in- 
fezione da $C$. $t$. rappresenti un fattore di rischio indipendente per lo sviluppo di carcinoma della cervice $(104,131)$, con un meccanismo biologico per il momento ancora oscuro. Si pensa che, in caso di infezione persistente, la Chsp 60 abbia un effetto antiapoptotico per cui l'accumulo di questa proteina nel citoplasma di cellule in attività replicativa potrebbe interferire con la regolazione della via apoptotica. La concomitante espressione di oncoproteine virali e/o la presenza di mutazioni, potrebbe portare alla capacità di sopravvivere agli stimoli apoptotici, alla perdita della senescenza replicativa e a una proliferazione incontrollata, con trasformazione neoplastica (30). DNA di C.t. o anticorpi anti Chsp 60 sono stati rilevati in pazienti con cancro della cervice $(82,121)$. Il sierotipo $\mathrm{G}$ di C.t. sembra essere quello maggiormente associato a questa patologia come evidenziato in un ampio studio di coorte scandinavo (530.000 donne). La presenza di sierotipi multipli sembrerebbe incrementare il rischio (3).

Occorrono comunque ancora studi per definire l'eventuale ruolo di C.t. nel cancro della cervice uterina.

\section{Infezioni neonatali e complicanze ostetriche}

C.t. è la più comune causa di congiuntivite ed una delle più comuni di polmonite neonatale. I nati da madri con infezione da C.t. sviluppano congiuntiviti nel $18-50 \%$ di casi e polmoniti nel $11-20 \%$. Sebbene nella maggior parte dei casi si tratti di contaminazione attraverso il canale del parto, sono stati riportati casi di infezioni in nati attraverso parto cesareo con membrane integre (98). La congiuntivite insorge generalmente in modo acuto ed unilaterale in un periodo variabile da 4 a 14 giorni dopo la nascita e se non trattata può estendersi all'altro occhio. Si tratta di un'infezione che tende spontaneamente alla risoluzione, ma che in alcuni casi può dar luogo alla formazione di pseudomembrane, cicatrici congiuntivali e micropanno corneale. Il tratto rinofaringeo risulta positivo in più dei due terzi dei casi $(25,72)$. Se non trattato, il neonato può presentare entro i tre mesi una pneumopatia interstiziale, senza febbre, con tosse simile a quella della pertosse, ma senza sibilo inspiratorio. In questo caso la diagnosi si basa sulla ricerca degli anticorpi specifici, essendo non sempre facile la ricerca dei microrganismi dagli aspirati bronchiali. Si ha infatti un aumento delle $\operatorname{IgG}$ e delle $\operatorname{IgM}$ o delle IgA sieriche spesso a titoli 4 volte superiori rispetto alla norma. Non bisogna tuttavia dimenticare che, nel neonato, la presenza di IgG di origine materna impone la ricerca parallela delle IgM o delle IgA. La presenza di IgM è considerato un segno patognomico di polmonite neonatale da C.t., così come è un para- metro diagnostico l'alto numero di neutrofili. Risultati sierologici suggeriscono una correlazione tra malattie polmonari croniche e le infezioni intrauterine da Chlamydia in nati con un peso molto basso $(25,72)$.

Come abbiamo già visto la prevalenza di infezione in gravidanza è sovrapponibile a quella della popolazione generale. Infezioni clamidiali non trattate durante la gravidanza sembrano associate a complicanze ostetriche quali aborto spontaneo, parto pretermine, rottura prematura delle membrane, basso peso alla nascita, morte neonatale ed endometriti post partum $(42,60,72)$.

\section{Nell'uomo \\ Uretriti}

C.t. è responsabile di circa il 50\% delle uretriti non specifiche (non gonococciche e post gonococciche) $(54,93,110)$. Decorre nel $30-50 \%$ dei casi in modo asintomatico o con sintomi lievi e banali (39). I sintomi, quando presenti, comprendono disuria, bruciori minzionali, dolore uretrale, e secrezioni spesso chiare e vischiose piuttosto che purulente, intermittenti, più frequenti al mattino. L'uretrite acuta, simile a quella gonococcica, è rara.

Il periodo d'incubazione è difficile da stabilire: in generale è compreso tra 7 e 14 giorni anche se può essere più corto, inferiore a 4 giorni.

Un uomo con un'uretrite asintomatica costituisce un'importante reservoir di infezione.

\section{Epididimiti}

Dall'uretra l'infezione può diffondere, per via ascendente, all'epididimo. Le epididimiti rappresentato uno dei più comuni problemi urologici. Il picco dell'incidenza si ha tra i 20 ed i 30 anni con il $70 \%$ dei casi (60). Negli uomini al di sotto dei 35 anni si tratta generalmente di un'infezione sessualmente trasmessa. Al di sopra dei 35 anni le epididimiti sono in genere causate da batteri del tratto urinario, soprattutto enterobatteri, non trasmessi per via sessuale $(31,58,132)$. Attualmente si ritiene che C.t. sia responsabile di circa il $30 \%$ dei casi [55\% negli uomini di età inferiore ai 35 anni (27)]. Si tratta in genere di un'epididimite unilaterale, raramente bilaterale. Nella forma acuta, che si manifesta soprattutto negli uomini giovani sono presenti gonfiore ed edema dell'epididimo, che può estendersi ai testicoli (orchite) $(27,132)$, a volte accompagnati da dolore scrotale, senso di pesantezza, febbre e malessere. Alla palpazione si nota un indurimento dell'epididimo, l'esame istologico mostra una fibrosi diffusa ed un infiltrato linfoplasmacitario e l'occlusione dei dotti eiaculatori è frequente (27). Più raramente può presentarsi come una massa scrotale che mima un tumore testicolare $(39,88,123)$.

Se non adeguatamente trattata l'epididimite può 
rappresentare, secondo alcuni autori, una causa di infertilità legata alla stenosi dell'epididimo, dei deferenti e dei dotti eiaculatori soprattutto quando l'infezione è bilaterale. Quando l'epididimite è accompagnata da orchite si potrebbe avere atrofia testicolare e azoospermia (27).

\section{Prostatiti}

La definizione e la classificazione delle prostatiti si basa sulla presenza di sintomi dolorosi associati o meno alla presenza di sintomi irritativi delle basse vie urinarie e sui risultati della diagnostica microscopica e/o microbiologica. Nel 1995 il National Institute of Health (NIH) statunitense ha introdotto uno schema classificativo basato su indagini eseguite su liquido seminale, secreto prostatico e mitto urinario post massaggio prostatico in cui si possono distinguere quattro condizioni: prostatite acuta batterica, prostatite cronica batterica, sindrome dolorosa pelvica cronica, comprendente la prostatite abatterica e la prostatodinia, e la prostatite asintomatica (64). Le prostatiti croniche rappresentano la più comune diagnosi in uomini d'età inferiore ai 50 anni e la terza in quelli d'età superiore. Nella maggior parte dei pazienti non è possibile mettere in evidenza un'infezione per cui spesso si parla di prostatiti abatteriche. Diversi autori hanno ipotizzato che C.t. possa essere uno degli agenti causali, ma mentre il suo ruolo nella patogenesi di uretriti e epididimiti è ben documentato, il suo ruolo nelle prostatiti è ancora oggi dibattuto e rimane controverso, in quanto i campioni utilizzati per la diagnosi (secrezioni prostatiche, urine dopo massaggio prostatico, liquido seminale) possono riflettere una contaminazione uretrale per l'inevitabile passaggio attraverso l'uretra $(39,125)$. Studi basati su quest'approccio diagnostico hanno comunque evidenziato C.t. in oltre il $25 \%$ dei casi $(75,81,88)$. Un altro approccio diagnostico è stato quello di eseguire le indagini su biopsia prostatica: in questi lavori C.t. è stata messa in evidenza nel $3-30 \%$ dei casi $(21,126)$. Altri lavori hanno anche valutato la presenza di IgA secretorie anti C.t. nelle secrezioni prostatiche e nel liquido seminale di pazienti con prostatiti, epididimiti o infertili: i dati dimostrano chiaramente che la presenza di IgA secretorie è un indicatore di infezione da C.t., ma non possono evidenziare il sito dell'infezione $(75,102)$. Ulteriori studi sono ancora necessari per chiarire, in modo definitivo, il ruolo di C.t. nelle prostatiti e nell'infezione cronico-persistente maschile.

\section{Infertilità maschile}

Anche per quanto riguarda l'infertilità maschile, il ruolo di C.t. è ancora controverso: a tutt'ora nessun lavoro ha potuto confermare una correlazione signficativa tra infezione da C.t. e infertilità maschile tanto che alcuni autori concludono che forse il solo aspetto importante di un'infezione nell'uomo è che costituisce un reservoir aumentando le possibilità di infezione nella donna.

Molti studi hanno cercato di correlare la presenza di markers sierologici di infezione pregressa con la qualità dello sperma, in realtà non sono state descritte differenze significative tra uomini con pregressa infezione e non $(63,83)$. Altri, pur confermando ciò, mettono in evidenza una stretta associazione tra assenza di concepimento e presenza di IgG anti Chlamydia nell'uomo indipendentemente dalla qualità dello sperma (57).

La presenza di anticorpi anti-Hsp 60 è stata messa in relazione con un aumento della leucospermia e dei livelli di citochine pro infiammatorie o di anticorpi anti spermatozoi. Inoltre il persistere della reazione infiammatoria potrebbe essere responsabile, a lungo termine, di una azoospermia su base ostruttiva $(27,34)$.

Studi in vitro hanno dimostrato che, incubando gli spermatozoi con C.t. serovar E, si assiste ad una diminuzione della motilità ed alla loro morte causata principalmente dal lipopolisaccaride che indurrebbe un'eccessiva produzione di ROS (reactive oxigen species). Il lipopolisaccaride di C.t. avrebbe un'azione spermicida maggiore di quella di altri microrganismi: circa 500 volte più attivo rispetto a quello di $E$. coli $(36,55)$.

Allo stato attuale delle conoscenze, gli effetti dell'infezione da C.t. sull'infertilità maschile sembrerebbero tuttavia legati soprattutto alla qualità della risposta immune (43).

\section{In entrambi i sessi}

\section{Linfogranuloma venereo}

Malattia sistemica causata dai serovars $\mathrm{L}_{1}, \mathrm{~L}_{2}$ e $\mathrm{L}_{3}$ di C.t., non comune nelle nazioni industrializzate ma largamente diffuso in Asia, Africa e Asia (50). Clinicamente il quadro è quello di una linfoadenopatia acuta a volte preceduta da una lesione primaria (ulcera erpetiforme, papula, pustola) o di una proctite ulcerativa con secrezioni rettali purulente. In assenza di terapia i linfonodi possono confluire in una massa fluttuante e dolente aderente ai piani profondi, andare incontro a suppurazione e rompersi dando luogo fistole multiple drenanti. In alcuni casi si ha progressione della malattia con distruzione dei tessuti e degli organi circostanti.

Considerata una malattia praticamente eradicata nei paesi occidentali è invece riapparsa negli ultimi anni. A partire dal 2003, i casi confermati di LGV sono stati 344 nel Regno Unito, 244 in Francia, 179 in Olanda, 61 in Germania. Pochi in altri Paesi europei: 8 in Belgio, 3 in Svezia e 1 in Spagna. Tutti i casi sono stati segnalati in omosessuali maschi e in alcuni bisessuali, ma in nessuna 
delle partner di questi. Tutti i pazienti hanno riportato comportamenti sessuali a rischio con numerosi partners anonimi $(78,117)$.

Nei Paesi Bassi e in Gran Bretagna sono state diagnosticate contemporaneamente negli stessi soggetti, un numero rilevante di infezioni di epatite $\mathrm{C}$ poiché probabilmente le lesioni rettali dovute al LGV favoriscono la trasmissione dell'HCV. Inoltre, nella maggioranza dei casi di LGV i pazienti erano anche HIV positivi, probabilmente non solo per ragioni epidemiologiche (appartenenza alla stessa popolazione a rischio) ma anche per motivi biologici (elevata suscettibilità immunologica all'acquisizione di altre infezioni). La presenza di proctiti e ulcere anogenitali, infatti, aumenta anche il rischio di trasmissione di HIV mentre l'immunodepressione, sembra favorire l'infezione da LGV. Sebbene la manifestazione clinica classica sia la sindrome inguinale, durante questa recrudescenza nei paesi occidentali il quadro clinico più frequente è stata la sindrome ano-rettale. Nella maggior parte dei casi, l'infezione è associata al serovar $\mathrm{L}_{2}(117)$.

\section{Artrite reattiva (Sindrome di Reiter)}

Una rara complicanza di un'infezione da C.t. non trattata, ma che può insorgere anche in seguito ad infezioni gastroenteriche, è rappresentata dalla sindrome di Reiter, un'artrite reattiva che associa la triade uretrite (a volte cervicite nelle donne), congiuntivite e lesioni mucocutanee non dolorose. Più frequente nell'uomo (rapporto 5:1 negli uomini rispetto alle donne) si manifesta da una a tre settimane dopo l'esordio dell'infezione da C.t. Ha una distribuzione mondiale, con un picco tra i $20 \mathrm{e}$ i 40 anni e si manifesta più frequentemente in pazienti con predisposizione genetica: il gene HLA-B27 è presente nel 70-80\% dei pazienti di razza bianca con tale sindrome (90). Anche in questo caso, il meccanismo patogenetico sembrerebbe legato alle $\mathrm{CHsp} 60$ che promuovono una risposta immunopatogena mediata da linfociti $\mathrm{T}$ che coinvolge siti d'infezione locali o periferici (41).

L'artrite reattiva è un'artrite infiammatoria che può essere causata da un vasto numero di microrganismi (batteri, virus e parassiti). Il coinvolgimento articolare è asimmetrico e può interessare più articolazioni contemporaneamente, in particolare delle estremità inferiori. Le lesioni mucocutanee sono rappresentate da eruzioni papulosquamose che si manifestano principalmente sul palmo delle mani e sulla pianta dei piedi. L'episodio iniziale dura abitualmente da tre a quattro mesi, ma può persistere anche per circa un anno (41).

\section{DIAGNOSI}

La diagnosi delle infezioni uro-genitali da C.t. si basa su due approcci:
1) la diagnosi diretta eseguibile mediante

- isolamento del microrganismo in colture cellulari

- metodi in immunofluorescenza

- tecniche immunoenzimatiche

-tecniche di biologia molecolare

2) la diagnosi indiretta, sierologica, che permette di ricercare gli anticorpi circolanti specifici.

\section{Diagnosi diretta}

La diagnosi diretta è relativamente semplice in corso di infezioni del basso apparato genitale, diviene più complessa quando si tratta di infezioni dell'apparato genitale alto soprattutto per la difficoltà di prelievo.

\section{Prelievo}

Essendo C.t. un parassita endocellulare, il prelievo, qualunque sia la metodica diagnostica utilizzata, dovrà contenere delle cellule.

\section{Prelievo endocervicale}

È necessario pulire bene la cervice uterina con un primo tampone per evitare di raccogliere solo muco; un secondo tampone viene ruotato per 1020 " nella cervice.

\section{Prelievo uretrale}

Si esegue introducendo il tampone per $1-2 \mathrm{~cm}$ nell'uretra anteriore e praticando un movimento rotatorio prima di estrarlo.

Secrezioni vaginali, prelievi vulvari, urine $1^{\circ}$ getto Dopo l'introduzione delle tecniche diagnostiche basate sull'amplificazione degli acidi nucleici (NAATs) anche questi prelievi possono essere utilizzati per la ricerca di C.t. Il vantaggio del loro utilizzo è dato dal fatto che si tratta di prelievi non invasivi che possono essere eseguiti dallo stesso paziente permettendo quindi, lo screening di popolazioni asintomatiche. L'utilizzo del $1^{\circ}$ getto di urine nella donna ha manifestato una sensibilità leggermente inferiore agli altri metodi, ma rappresenta comunque un buon prelievo se utilizzato nel quadro di un programma di screening.

\section{Prelievi dall'apparato genitale alto}

Si tratta, nella maggior parte dei casi di biopsie tubariche, aderenze prelevate in corso di laparoscopia o liquido peritoneale del Douglas.

\section{Sospetto di linfogranuloma venereo}

Il prelievo è ottenuto per puntura del linfonodo.

\section{Prelievo oculare}

Si esegue praticando un leggero scraping della con- 
giuntiva inferiore eliminando le secrezioni purulente. Prelievi dall'apparato respiratorio nel neonato

Si tratta generalmente di un aspirato tracheale o di un tampone faringeo

Isolamento e identificazione in coltura cellulare. Utilizza monostrati cellulari di cellule McCoy o Hela 229 e rileva la presenza di inclusioni intracellulari tipiche di C.t. Per quanto questa tecnica fornisca la prova inconfutabile della presenza di C.t. non è mai stata una metodica di routine perché decisamente complessa, costosa e non standardizzabile. La coltura cellulare è stata per lungo tempo considerata il "gold standard" poiché ha una specificità del $100 \%$, ma la sua sensibilità varia dal 50 al $90 \%$ secondo i diversi studi $(1,8,47,101)$. La sensibilità è legata anche al numero di microrganismi presenti nel campione e al loro stato replicativo: la presenza di una forma persistente di C.t. sfugge all'isolamento. Una terapia antibiotica, la citotossicità di alcuni prelievi (urine, sperma), la cattiva conservazione dei prelievi (richiede la vitalità e l'integrità del microrganismo) possono portare a risultati falsamente negativi $(1,47)$. L'interesse di questa metodica risiede nella possibilità di isolare $i$ ceppi per studi epidemiologici e di sensibilità agli antibiotici.

\section{Metodi in immunofluorescenza (IFD)}

Permettono la rilevazione di antigeni specifici del genere Chlamydia o di specie Chlamydia trachomatis. Utilizzano anticorpi monoclonali marcati con isotiocianato di fluoresceina, che mettono in evidenza i CE extracellulari (perfettamente rotondeggianti, di $300 \mathrm{~nm}$ e dalla brillante fluorescenza verde mela), più raramente gli inclusi, su un tappeto di cellule epiteliali che permettono il controllo della qualità del prelievo. La specificità è maggiore con gli anticorpi monoclonali anti MOMPS, specificità per C.t., che anti LPS specificità di genere Chlamydia.

Questa metodica ha il vantaggio di permettere una diagnosi rapida, anche se necessita di personale specializzato in grado di discriminare gli eventuali artefatti del preparato, ed è l'unica che permette di valutare l'idoneità del preparato. Un campione è considerato positivo in presenza di un numero minimo di CE variabili da 1 a 10 secondo i diversi studi. Un campione negativo non deve contenere nessun $\mathrm{CE}$ in presenza di almeno 50 cellule epiteliali. Un altro vantaggio è rappresentato dal fatto che non è necessaria la presenza di microrganismi vivi, tuttavia questa metodica non può essere utilizzata su prelievi quali liquido peritoneale o biopsie tubariche e non è applicabile a grandi serie di campioni. La sua sensibilità è abbastanza elevata, tra 1'80-90\% e la specificità tra il $98-99 \%(8,47)$.

\section{Metodi immunoenzimatici (EIA)}

Si basa sul legame anticorpo (anti LPS, anti MOMP) fissato su un supporto solido e antigene, presente nel campione. Un anticorpo secondario legato ad un enzima di rivelazione (perossidasi, fosfatasi alcalina), si lega al complesso e l'intensità della colorazione viene rilevata da uno spettrofotometro. Queste tecniche hanno il vantaggio di consentire una diagnosi rapida, di essere automatizzabili e standardizzabili con la possibilità di analizzare grosse serie. Non necessitano di grande esperienza del personale e consentono la diagnosi anche in assenza di microrganismi vivi. Il limite è dato dalla scarsa sensibilità $(50-60 \%)$ soprattutto quando il prelievo contiene pochi microrganismi o in caso di infezioni persistenti. Un altro svantaggio è dato dal fatto che gli anticorpi anti LPS posso cross-reagire con altri microrganismi Gram negativi e dare falsi positivi per cui è sempre necessario un test di conferma (8).

Ampiamente utilizzati sono anche test rapidi ("point of care tests") che utilizzano tecniche EIA basate principalmente sulla cattura su membrana o sull'immunodiffusione al lattice. Sono rapidi (risultati in circa $30 \mathrm{~min}$ ), di facile esecuzione, non richiedono personale addestrato e particolare attrezzatura, possono essere utilizzati negli studi medici. Utilizzando anticorpi diretti contro LPS, specifico di genere, possono dare falsi positivi, dovuti a cross-reazioni con LPS di altri microrganismi. Questi test hanno una sensibilità e una specificità inferiore a quelle dei test immunoenzimatici eseguiti in laboratorio. Un risultato positivo dovrebbe essere sempre confermato $(1,8,47)$.

Tabella 2. Sensibilità e specificità dei metodi diagnostici

\begin{tabular}{lll}
\hline Metodo & Sensibilità & Specificità \\
\hline Coltura & $70-85 \%$ & $100 \%$ \\
\hline IFD & $70-90 \%$ & $95-100 \%$ \\
\hline EIA & $60-80 \%$ & $95-98 \%$ \\
\hline NAATs & $90-100 \%$ & $98-100 \%$ \\
\hline
\end{tabular}

\section{Tecniche di rivelazione degli acidi nucleici}

Le tecniche di biologia molecolare rendono possibile la ricerca di C.t. non solo nei campioni classici (tamponi endocervicali o uretrali), ma anche in quelli non utilizzabili per la coltura (sperma, urine) e rilevano gli acidi nucleici del genoma batterico con tecniche di ibridizzazione molecolare o dopo amplificazione. Utilizzano delle sonde o dei primers diretti contro un target di natura variabile: DNA cromosomico o plasmidico, DNA codificante per RNA cromosomico, RNA ribosomico.

La ricerca di C.t. con sonde DNA è eseguita con tecniche di ibridazione in situ o in mezzo liquido. L'ibridazione in situ con sonde specifiche, ha permesso di osservare la persistenza di C.t. nelle tube 
di donne con sterilità tubarica (47).

Più recentemente sono stati introdotti nella pratica diagnostica, test basati sull'amplificazione di acidi nucleici (NAATs). L'amplificazione del genoma permette di produrre un numero molto elevato di sequenze geniche identiche e di migliorare la sensibilità del test (101). Questi metodi amplificano sia un gene cromosomico, il gene omp 1 codificante per il MOMP, sia l'RNAr presente in circa 1000 copie per microrganismo, sia una sequenza del plasmide criptico specifico di C.t. presente nel $99 \%$ dei ceppi in 10 copie per batterio (40). I test che amplificano l'RNAr hanno una sensibilità ancora maggiore rispetto a quelli che amplificano il DNA anche se l'RNA è più fragile. Tra le tecniche oggi in commercio, la PCR (Polimerase Chian Reaction) e 1'SDA (Strand Displacement Amplification) amplificano il DNA plasmidico mentre la TMA (Transcription Mediated Amplification) amplifica l'RNA dopo una trascrizione inversa in DNA complementare. I NAATs hanno un'elevata sensibilità e specificità, non richiedono la presenza di microrganismi vitali, permettono di individuare anche un basso numero di microrganismi e i risultati possono essere ottenuti in poche ore anche se non permettono di risalire al numero di microrganismi presenti nel campione. Recentemente le tecniche di PCR real time permettono anche di quantificare il prodotto dell'amplificazione: l'aumento di un segnale di emissione fluorescente è direttamente proporzionale alla quantità di amplificato prodotto.

L'elevata sensibilità (>90\%) e specificità (>98\%) rendono questi test i migliori per la diagnosi delle infezioni da C.t. $(18,107)$. Dati della letteratura indicano che l'uso di metodi non amplificati, soprattutto nello screening di popolazioni a medio-basso rischio, si traduce in una globale diminuzione della prevalenza dell'infezione (fino al $15-30 \%$ se si usa la coltura cellulare) e di conseguenza in un aumento dei casi non individuati e quindi non trattati (13). Il loro limitato utilizzo dovuto al costo elevato, alla relativa complessità tecnologica ed alla suscettibilità ai fenomeni di contaminazione con risultati falsamente positivi è stato risolto dalla loro standardizzazione e automazione e dall'introduzione in commercio di test dal costo più contenuto. L'impiego di NAATs consente di diagnosticare un'infezione da C.t. con un elevato grado di sensibilità e specificità utilizzando anche campioni "alternativi" rispetto ai classici tamponi uretrali e cervicali come il primo getto di urine, i tamponi vaginali o vulvari $(67,101)$.

La diagnosi di infezione da C.t., basata sull'utilizzo del tampone vaginale, si attesta su livelli di efficacia pari o superiori ai più tradizionali mezzi di indagine mediante coltura ed ai più moderni metodi di indagine mediante tecniche di amplificazione su campioni di urine o tamponi cervicali. Diversi studi $(96,103)$ hanno confermato la validità dell'autoprelievo vaginale confrontato con prelievi endocervicali e vaginali eseguiti da personale specializzato dimostrando rispettivamente una sensibilità del $100 \%$ ed una specificità del $98.5 \%$.

L'alta sensibilità dei NAATs permette inoltre di utilizzare "pools" di campioni per ridurre i costi. Aliquote di ciascun campione possono essere combinate in un pool e testate. Se il pool risulta negativo, tutti i campioni formanti il pool saranno negativi, se il pool è positivo verranno testati singolarmente i campioni che lo compongono $(18,23,40)$. Un limite dei NAATs è rappresentato dal fatto che nel campione possono essere presenti inibitori della reazione di amplificazione responsabili di risultati falsamente negativi. La natura di tali inibitori è poco conosciuta e la quantità è legata al tipo di campione, la loro influenza diminuisce con la diluizione o con il congelamento (18).

$\mathrm{Va}$ inoltre ricordato che il successo o il fallimento di una terapia mirata non possono essere valutati prima di 3-4 settimane, il tempo necessario alla completa eliminazione degli acidi nucleici.

\section{Sierodiagnosi}

Anche se non ha lo stesso valore diagnostico della ricerca diretta la sierologia é indubbiamente di grande aiuto nella diagnosi delle complicanze genitali e generali e soprattutto nella valutazione dell'infertilità tubarica o della $\operatorname{MIP}(35,80,114,118)$. La sierodiagnosi si basa sulla ricerca di anticorpi delle classi IgG, A, M utilizzando tecniche di immunofluorescenza indiretta, immunoperossidasi o immunoenzimatiche.

Tabella 3. Strategie diagnostiche nell'infezione da C.t. (Da Hamdad et al 2004, mod.)

\begin{tabular}{|c|c|c|c|c|c|c|}
\hline & \multirow{2}{*}{$\begin{array}{l}\text { Infezioni del basso } \\
\text { apparato genitale } \\
\text { Endocervice, uretra }\end{array}$} & \multicolumn{3}{|c|}{ Screening } & \multicolumn{2}{|c|}{$\begin{array}{c}\text { Infezioni dell'apparato genitale } \\
\text { alto }\end{array}$} \\
\hline & & Endocervice & $I^{\circ}$ getto urine & Vagina, vulva & Endocervice & Biopsia tubarica \\
\hline $\begin{array}{l}\text { Coltura } \\
\text { cellulare }\end{array}$ & +++ & + & - & - & $+/-$ & - \\
\hline IFD & +++ & + & - & - & - & - \\
\hline EIA & ++ & + & - & - & - & - \\
\hline Ibridazione & ++ & + & - & - & - & - \\
\hline NAAT & +++ & +++ & +++ & +++ & +++ & +++ \\
\hline
\end{tabular}

+++ : molto sensibile, ++ : sensibile, + :media sensibilità, + /-:poco sensibile, -:non indicato 
La necessità di avere a disposizione metodi rapidi, semplici ed allo stesso tempo affidabili per la sierodiagnosi di queste infezioni ha permesso lo sviluppo di tecniche ELISA che usano come antigeni particolari proteine ricombinanti di C.t. (rELISA).

Il test più comunemente usato è la microimmunofluorescenza (MIF) considerato a tutt'oggi il "gold standard" anche se ha diverse limitazioni. Introdotto nel 1970 da Wang e Grayston (122) per la classificazione dei vari sierotipi, è stato adattato in seguito per la ricerca di anticorpi sierici. Un'altra metodica diffusa è l'immunoperossidasi indiretta (IPA). Questo test in cui vengono utilizzati come antigeni cellule infettate da C.t. serovar L2, permette la titolazione delle varie classi anticorpali, ma non esclude cross-reazioni.

L'interpretazione di questi test è tuttavia delicata sia per la presenza di antigeni comuni alle tre specie di Chlamydia (trachomatis, psittaci e pneumoniae) (19) sia per la persistenza degli anticorpi a volte anche per anni dopo l'infezione.

Un titolo anticorpale di IgG isolato anche se relativamente elevato non implica necessariamente un'infezione evolutiva, ma deve comunque far pensare ad una complicanza.

La presenza di IgA é indicativa di un'intensa reazione tissutale e spesso di un'alterazione tubarica ma non indica specificatamente un'infezione acuta. Le IgA sono infatti evidenziate con la stessa frequenza nelle infezioni acute come in quelle croniche e possono persistere anche per anni dopo la positivizzazione iniziale.

Le IgM indicano un'infezione primaria o una reinfezione attiva e rappresentano un buon indice di infezione profonda essendo presenti nel $60 \%$ delle salpingiti acute e nel $20 \%$ di quelle croniche. La loro persistenza anche dopo terapia deve far pensare ad una mancata guarigione ed alla presenza di sequele.

Recentemente si è diffuso l'uso di test sierologici come il Western Blot, che permettono di rivelare la presenza di anticorpi specifici diretti verso diverse proteine di C.t. come la CHsp 60. Diversi studi hanno dimostrato la stretta associazione tra la presenza di anticorpi anti-Hsp 60 e lo sviluppo di sequele infiammatorie croniche $(5,112)$.

\section{BIBLIOGRAFIA}

1. AAVV. Place des tecniques de biologie moleculaire dans l'identification des infections uro-genitales basses à Chlamydia trachomatis. Rapport ANAES, 2003, Tome 1.

2. Adams EJ, Charlett A, Edmunds WJ, et al. Chlamydia trachomatis in the United Kingdom: a systematic review and analysis of prevalence stu- dies. Sex Transm Infect, 2004; 80(5): 354-62.

3. Anttila T, Saikku P, Koskela P, et al. Serotypes of Chlamydia trachomatis and risk for development of cervical squamous cell carcinoma. JAMA, 2001; 285: 47-51.

4. Banikarim C, Chacko MR, Wiemann CM, Smith $\mathrm{PB}$. Gonorrhea and Chlamydia screening among young women: stage of change, decisional balance, and self-efficacy. J Adolesc Health, 2003; 32: 28895.

5. Bas S, Muzzin P, Ninet B, Bornand JE, Scieux C, Vischer TL. Chlamydial serology: comparative diagnostic value of immunoblotting, microimmunofluorescence test, and immunoassays using different recombinant proteins as antigens. J Clin Microbiol 2001 Apr; 39(4): 1368-77.

6. Bax CJ, Trimbos JB, Spaargaren J. Chlamydia trachomatis heat shock protein (CHsp 60) antibodies in women without and with tubal pathology using a new commercially available assay. Sex Transm Infect, 2004; 80: 415-21.

7. Bell TA, Stamm WE, Kuo CC, et al. Risk of perinatal transmission of Chlamydia trachomatis by mode of delivery. Journal of Infection, 1994; 29(2):165-9.

8. Black CM. Current Methods of laboratory diagnosis of Chlamydia trachomatis infections. Clinical Microbiology Reviews, 1997; 10(1): 160-84.

9. Blake DR, Kearney MH, Oakes JM, Druker SK, Bibace R. Improving participation in Chlamydia screening programs: perspectives of high-risk youth. Arch Pediatr Adolesc Med, 2003; 157: 523-9.

10. Bush RM, Everett KDE. Molecular evolution of the Chlamydiaceae. Int J Syst Evol Microbiol, 2001; 51: 203-20.

11. Centers for Disease Control and Prevention. Chlamydia trachomatis genital infections- United States. 1995. Morb Mortal Wkly Rep, 1997; 46(9): 193-8.

12. Centers for Disease Control and Prevention: Chlamydia screening among sexually active young female enrollees of health plans-United States, 1999-2001. Morb Mortal Wkly Rep, 2004; 53: 9835.

13. Centers for Disease Control and Prevention: Screening Tests to detect Chlamydia trachomatis and Neisseria gonorrheae Infections. Morb Mortal Wkly Rep 2002; 51: 15.

14. Cevenini R, Donati M, Sembri V. Chlamydia trachomatis - the agent. Best Pract Res Clin Obstet Gynaecol, 2002; 16(6): 761-73.

15. Chacko MR, Von Sternberg K, Velasquez MM. Gonorrhea and Chlamydia screening in sexually active young women: the processes of change. J Adolesc Health, 2004; 34: 424-7.

16. Chacko MR, Wiemann C, Kozinetz CA, et al. New sexual partners and readiness to seek screening for Chlamydia and Gonorrhea: Predictors among young women. Journal of Adolescent Health, 2005; 36: 133.

17. Chernesky M, Castriciano S, Jang D, Smieja M. Use of flocked swabs and a universal transport medium to enhance molecular detection of Chlamydia trachomatis and Neisseria gonorrheae. J Clin Microb, 2006; 44(3): 1084-6.

18. Chernesky M, Chong S Jang D, et al. Inibition of amplification of Chlamydia trachomatis plasmid DNA by the ligase chain reaction associated with female urines. Clin Microbiol Infect 1998; 4: 397404.

19. Chesson HW, Blandford JM, Gift TL, Tao G, Irwin 
KL. The estimated direct medical cost of sexually transmitted diseases among American youth, 2000. Perspect Sex Reprod Health. 2004; 36: 11-9.

20. Clad A, Prillwitz J, Hintz KC, et al. Discordant prevalence of Chlamydia trachomatis in asymptomatic couples screened using urine ligase chain reaction. European Journal of Clinical Microbiology and Infectious Disease 2001; 20: 324-8.

21. Corradi Gy, Bucsek M, Panovics J, et al. Detection of Chlamydia trachomatis in prostate by transmission electron microscopy. Int J Androl, 1996; 19: 109-12.

22. Crossman SH, MD. The challenge of Pelvic Inflammatory Disease. Am Fam Physician, 2006; 73: 859-64.

23. Currie MJ, McNiven M, Yee T, et al. Pooling of clinical specimens prior to testing for Chlamydia trachomatis by PCR is accurate and cost saving. J Clin Microb 2004; 42 (10): 4866-7.

24. Darroch J, Myers L, Cassell J. Sex differences in the experience of testing positive for genital Chlamydia infection: a qualitative study with implication for public health and for a national screening programme. Sex Transm Infect, 2003; 79: 372-3.

25. Darville T. Chlamydia trachomatis: Infections in neonates and young children. Semin Pediatr Infect Dis, 2005; 16: 235-44.

26. De Barbeyrac B, Bébéar C. Histoire naturelle des infections à Chlamydia physiopathologie des infections à Chlamydia: Conséquences diagnostiques et thérapeutiques. Archives de pediatrie, 2005; 12: 2631.

27. Delavierre D. Orchi- epididymitis. Annales d'urologie, 2003; 37: 322-38.

28. Den Hartog JE, Land JA, Stassen FR, et al. Serological markers of persistent C. trachomatis infections in women with tubal factor subfertility. Hum Reprod, 2005; 20: 986-90.

29. Department of Health and Human Services. Atlanta: Center for Disease Control and Prevention, 2006. Sexually Transmitted Disease Surveillance 2005 Supplement. Chlamydia Prevalence Monitoring Project Annual Report 2005.

30. Di Felice V, David S, Cappello F. et al. Is chlamydial heat shock protein 60 a risk factor for oncogenesis? CMLS, 2005; 62: 4-9.

31. Drury NE, Dyer JP, Breitenfeldt N, et al. Management of acute Epididymitis: are European Guidelines being followed? European Urology, 2004; 46: 522-525.

32. Eckert LO, Hawes SE, Wolner-Hanssen PK, et al. Endometritis: the clinical-pathologic syndrome Am J Obstet Gynecol, 2002; 186(4): 690-5.

33. Egger M, Low N, Smith GD, et al. Screening for chlamydial infections and the risk of ectopic pregnancy in a county in Sweden: ecological analysis. BMJ, 1998; 316 (7147): 1776-80.

34. Egger-Kruse W, Neur A, Clussmann C, et al. Seminal antibodies $60 \mathrm{kda}$ heat shock protein (HSP $60)$ in male partners of subfertile couples. Hum Reprod, 2002; 17 (3):726-35.

35. Eggert-Kruse W, Rohr G, Demirakca T, et al. Chlamydial serology in 1303 asymptomatic subfertile couples. Hum Reprod, 1997; 12 (7):1464-75.

36. Eley A, Pacey AA, Galdiero M, Galdiero M, Galdiero F. Can Chlamydia trachomatis directly damage your sperm? Lancet Infect Dis, 2005; 5(1): 53-7.

37. Fenton KA, Mercer CH, Johnson AM, Byron CL, et al. Reported sexually transmitted disease clinic attendance and sexually transmitted infections in Britain: prevalence, risk factors and proportionate population burden. J Infect Dis, 2005; 191(1): 12738.

38. Finelli L, Nakashima AK, Hillis S, Crayne E, Spitalny KC. Selective screening versus presumptive treatment criteria for identification of women with chlamydial infection in public clinics: New Jersey. Am J Obstet Gynecol, 1996; 174: 1527-33.

39. Florian ME, Wagenlehner, et al. Chlamydial infections in urology. World J Urol, 2006; 24: 4-12.

40. Fredlund H, Falk L Jurstrand M, et al. Molecular genetic methods for diagnosis and characterisation of Chlamydia trachomatis and Neisseria gonorrhoeae: impact on epidemiological surveillance and interventions. APMIS, 2004; 112: 771-84.

41. Galadari I, Galadari H. Nonspecific urethritis and reactive arthritis. Clinic Dermatol, 2004; 22: 469-75.

42. Gencay M, Koskiniemi M, Fellman V, et al. Chlamydia trachomatis infection in mothers with preterm delivery and in their newborn infants. APMIS, 2001; 109 (9): 636-40.

43. Gonzales GF, Munoz G, Sànchez R, et al. Update on the impact of Chlamydia trachomatis infection on male fertility. Andrologia, 2004; 36: 1-23.

44. Götz HM, Van Bergen JEAM, Veldhuijzen IK, et al. A prediction rule for selective screening of Chlamydia trachomatis infection. Sex Transm. Inf, 2005; 81: 24-30.

45. Grimley DM, Annang L, Houser S, Chen H. Prevalence of condom use errors among STD clinic patients. Am J Health Behav, 2005; 29 (4): 324-30.

46. Haggerty CL, PhD, MPH, Peipert JF. Predictors of chronic pelvic pain in an urban population of women with symptoms and sign of pelvic inflammatory disease. Sex Transm Dis 2005; 32 (5): 293-9.

47. Hamned F, Orfila J, Boulanger JC, Eb F. Chlamydia trachomatis urogenital infections in women. Best diagnosis approaches. Gynécol Obstétr \&Fertilité, 2004; 32: 1064-74.

48. Han Y, Coles FB, Hipp S. Screening criteria for Chlamydia trachomatis in family planning clinics: accounting for prevalence and client's characteristics. Fam Plann Perspect, 1997; 29: 163-6.

49. Hermann B, Egger M. Genital Chlamydia trachomatis infections in Uppsala County, Sweden, 19851993: declining rates for how much longer? Sex Transm Dis 1995; 22 (4): 253-60.

50. Herring A, Richens J. Lymphogranuloma venereum. Sex Transm Infect, 2006; 82 (4): 23-25.

51. Hogan RJ, Mathews SA, Mukhopadhyay S, et al. Chlamydial persistence: beyond the biphasic paradigm. Infect Immun., 2004; 72(4): 1843-55. Review.

52. Holmes KK, Sparling PF, Mardh P-A, et al (eds). Sexually transmissible infectious agents in sexually active and virginal asyntomatic adolescent girls. Pediatrics. 1999; McGraw-Hills, cap 6.

53. Honey E, Augood C, Templeton A, Russell I, Paavonen J, et al. Cost effectiveness of screening for Chlamydia trachomatis: a review of published studies. Sex Transm Infect, 2002; 78(6): 406-12.

54. Horner P, Thomas B, Gilroy, et al. Role of Mycoplasma genitalium and Ureaplasma urealyticum in acute and chronic non gonococcal urethritis. Clin Infect Dis, 2001; 32: 995-1003.

55. Hossenzadeh S, Brewis IA, Elay A, et al. Co-incubation of human spermatozoa with Chlamydia trachomatis serovar E causes premature sperm death. Hum Reprod, 2001; 16: 293-99.

56. Hu D, Hook EW 3rd, Goldie SJ. Screening for 
Chlamydia trachomatis in women 15 to 29 years of age: a cost-effectiveness analysis. Ann Intern Med, 2004; 141 (7): 501-13.

57. Idahl A, Boman J, Kumlin U, et al. Demostration of Chlamydia trachomatis IgG antibodies in the male partner of the infertile couple is correlated with a reduced likehood of the achieving a pregnancy, Hum Reprod 2004; 19: 1121-26.

58. Joly-Guillon ML, Lasry S. Practical recommendations for the drug treatment of bacterial infections of the male genital tract including urethritis, epididymitis and prostatis. Drug, 1999; 57: 743-50.

59. Kamwendo F, Forslin L, Bodin L, Danielsson D. Decreasing incidences of gonorrhoea and Chlamydia associated acute pelvic inflammatory disease. A 25 year study from an urban area of central Sweden. Sex Transm Dis, 1996; 23(5): 384-91.

60. Karinen L. Chronic Chlamydial Infection: impact on human reproductive health, Acta Univ Oul D 872, 2006.

61. Klavs I, Rodrigues L C, Wellings K, Kese D, Hayes R. Prevalence of genital Chlamydia trachomatis infection in the general population of Slovenia: serious gaps in control. Sex Transm Inf, 2004; 80: 121-3.

62. Kobayashi Y, Takeuchi H, Kitade M, Kikuchi I, Sato Y, Kinoshita K. Pathological study of Fitz-HughCurtis syndrome evaluated from fallopian tube damage. J Obstet Gynaecol Res, 2006; 32(3): 280-5.

63. Krause W, Bohring C. Male infertility and genital chlamydial infections: victim or perpetrator? Andrologia, 2003; 35: 209-16.

64. Krieger JN, Nyberg L, Nickel J. NIH consensus definition and classification of Prostatitis. JAMA, 1999; 282: 236-7.

65. LaMontagne DS, Fenton KA, Randall S, et al. On behalf of the National Chlamydia Screening Steering Group: Estabilishing the National Chlamydia Screening Programme in England: results from the first full year of screening. Sex Transm Infect, 2004; 80: 335-41.

66. Latino MA, De Intinis G, Rosso C, De Maria D, Intorcia P, Caneparo A. Prevalenza dell'infezione da Chlamydia trachomatis in una popolazione giovanile. Congresso AMCLI, Torino, 19-22 /09/06.

67. Logan S, Browne J, McKenzie H, et al. Evaluation of endocervical, first-void urine and self-administered vulval swabs for detection of Chlamydia trachomatis in a miscarriage population. BJOG, 2005;112: 10-106.

68. Low N. Current status of Chlamydia screening in Europe. Eurosurveillance, 2004; 8: 68-9.

69. Luzzi GA, O'Brien TS. Acute epididymitis. BJU Int, 2001; 87 (8): 747-55.

70. Manavi K. A review on infection with Chlamydia trachomatis. BEST Pract \& Research, 2006; 20 (6): 941-51.

71. Mangione-Smith R, O'Leary J, McGlynn EA. Health and cost-benefits of Chlamydia screening in young women. Sex Transm Dis, 1999; 26(6): 309-16.

72. Mardh Per-Anders. Influence of infection with Chlamydia trachomatis on pregnancy outcome, infant health and life-long sequelae in infected offspring. Pract \& Research, 2002; 16 (6): 847-64.

73. Matteelli A, Beltrame A, Carvalho AC, Casalini C, et al. Chlamydia trachomatis genital infection in migrant female sex workers in Italy. Int J STD AIDS, 2003; 14 (9): 591-5.

74. Mavrov I, Bondarenko GM. The evolution of sexually transmitted infections in the Ukraine. Sex
Transm Inf 2002; 78: 219-21.

75. Mazzoli S, Bani D, Salvi A, et al.: In vivo evidence of Chlamydia trachomatis muniature reticulary bodies (MRB) as a persistence markers in chronic Prostatitis. In: Proceedings of the fourth meeting of the European society for Chlamydia research, Helsinki, 2000.

76. Mc Millan HM, O'Carroll H, Lambert JS, et al. Screening for Chlamydia trachomatis in women attending outpatient clinics in a large maternity hospital in Dublin, Ireland. STI online first, 2006.

77. Mikl J, Sudar Z, Smith PF, Bruckova M, et al. HIV infection and high risk behavior among patients attending an STD referral clinic in Prague, Czech Republic. Sex Transm Inf 1998; 74: 128-30.

78. Miller KE. Diagnosis and treatment of Chlamydia trachomatis infection. Am Fam Physician 2006; 73: 1411-6.

79. Miller WC, Ford CA, Morris M, Handcock MS, et al. Prevalence of chlamydial and gonococcal infections among young adults in the United States. JAMA, 2004; 291(18): 2229-36.

80. Mouton JW, Peeters MF, van Rijssort-Vos JH, Verkooyen RP. Tubal factor pathology caused by Chlamydia trachomatis: the role of serology. Int J STD AIDS 2002; 13 (2): 26-9.

81. Mutlu N, Mutlu B, et al.: The role of Chlamydia trachomatis in patients with non-bacterial Prostatitis. Int J Clin Pract, 1998; 52: 540-1.

82. Ness RB, Goodman MT, Shen C, Brunham RC. Serologic evidence of past infection with Chlamydia trachomatis, in relation to ovarian cancer. J Infect Dis, 2003; 187 (7): 1147-52.

83. Ness RB, Markovic N, Carlson C, et al. Do men become infertile after having sexually transmetted urethras? An epidemiological examination. Fertil Steril, 1997; 68: 205-13.

84. Norman J. Epidemiology of female genital Chlamydia trachomatis infections. Best Pract Res Clin Obstet Gynaecol, 2002; 16 (6): 775-87. Review.

85. Norman JE, Wu O, Twaddle S, et al. An evaluation of economics and acceptability of screening for Chlamydia trachomatis infection, in women attending antenatal, abortion, colposcopy and family planning clinics in Scotland, UK. Bjog, 2004; 111: 1261-8.

86. Nozu T, Komiyama H. Fitz-Hugh-Curtis syndrome. Intern Med, 2006; 45(4): 221-2.

87. Oakeshott P, Kerry S, Hay S, Hay P. Opportunistic screening for chlamydial infection at time of cervical smear testing in general practice: prevalence study. BMJ, 1998; 316: 351-2.

88. Ostaszewska I, 2000, Zrodowska-Stefanow B, et al. Role of Chlamydia in Epididymitis. Part II Clinical diagnosis. Med Sci Monit, 2000; 6 (6): 1119-21.

89. Ostergaard L, Andersen B, Moller JK, Olesen F. Home sampling versus conventional swab sampling for screening of Chlamydia trachomatis in women: a cluster-randomized 1-year follow-up study. Clin Infect Dis, 2000; 31(4): 951-7.

90. Ozgul A, Dede I, Taskaynatan MA, et al. Clinical presentations and non- chlamydial reactive arthritis. Rheumatol Int, 2006; 26: 879-85.

91. Paavonen J. Pelvic inflammatory disease. From diagnosis to prevention. Dermatology Clinics, 1998; 16: 747-56.

92. Pavlin NL, Gunn JM, Parker R, et al. Implementing Chlamydia screening: what do women think? A sistematic review of the literature. BMC Public 
Health, 2006; 6: 221

93. Pepin J, Sobela F, Deslandes S, et al. Etiology of discharge in West Africa: the role of Mycoplasma genitalium and Trichomonas vaginalis. Bulletin of the World Health Organization, 2001; 79: 118-26.

94. Persson K. The role of serology, antibiotic susceptibility testing and serovars determination in genital chlamydial infections. Best Pract \& Research, 2002; 16 (6): 801-2.

95. Pimenta JM, Catchpole M, Rogers PA, Perkins E, et al. Opportunistic screening for genital chlamydial infection. I: acceptability of urine testing in primary and secondary healthcare settings. Sex Transm Infect, 2003; 79: 16-21.

96. Polaneczky M, Quigley C, Pollock L, Dulko D, Witkin SS. Use of self-collected vaginal specimens for detection of Chlamydia trachomatis infection. Obstet Gynecol, 1998; 91(3): 375-8.

97. Quinn TC, Gaydos CD, Shepherd MMS, et al. Epidemiologic and Microbiologic Correlates of Chlamydia trachomatis infection in sexual partnerships. JAMA, 1996; 276: 1737-42.

98. Ratelle S, Keno D, et al. Neonatal chlamydial infections in Massachusetts, 1992-1993. Am J Prev Med. 1997 May-Jun; 13(3): 221-4.

99. Santer M, Wyke S, Warner P. Women's experiences of Chlamydia screening. Qualitative interviews with women in primary care. Eur J Gen Pract, 2003; 9: 56-61.

100. Schachter J, Chow JM, Howard H, et al. Detection of Chlamydia trachomatis by Nucleic Acid Amplification Testing: our evaluation suggest that CDC-Recommended approaches for confirmatory testing are ill-advided. J Clin Microb, 2006; 44 (7): 2512-7.

101. Schachter J, McCormack WM, Chernesky MA, et al. Vaginal swabs are appropriate specimens for diagnosis of genital tract infection with Chlamydia trachomatis. J Clin Microb 2003; 41: 3784-9.

102. Schuppe HC, Bispink G, Peet DJ, et al. The significance of antibodies against $\mathrm{C}$. trachomatis in seminal plasma. In: Proceedings of the fourth meeting of the European society for Chlamydia research Helsinki, 2000.

103. Shafer MA, Moncada J, Boyer CB, Betsinger K, Flinn SD, Schachter J. Comparing first-void urine specimens, self-collected vaginal swabs, and endocervical specimens to detect Chlamydia trachomatis and Neisseria gonorrhoeae by a nucleic acid amplification test. J Clin Microbiol;2003; 41(9): 4395-9.

104. Smith JS, Bosetti C, Munoz N, Herrero R, et al. Chlamydia trachomatis and invasive cervical cancer: a pooled analysis of the IARC multicentric casecontrol study. Int J Cancer, 2004; 111(3): 431-9.

105. Spiliopoulov A, Lakiotis V, Vittoraki A. Chlamydia trachomatis: time for screening? Clin Microbiol Infect, 2005; 11: 687-9.

106. Stephens RS. Introduction. In Stephens RS (ed.). Chlamydia: Intracellular Biology, Pathogenesis and Immunity, ppxi-xxiii. Washington, DC: American Society for Microbiology Press, 1999.

107. Steven-Simon C, MD, Sheeder J, MSPH. Chlamydia trachomatis: Common Misperceptions and Misunderstandings. J Pediatr Adolesc Gynecol 2005; 18: 231-43.

108. Suss AL, Homel P, Hammerschlag M, Bromberg K. Risk factors for pelvic inflammatory disease in inner-city adolescents. Sex Transm Dis, 2000; 27: 289-91.

109. Tajiri T, Tate G, Iwaku T, Takeyama N, et al. Right pleural effusion in Fitz-Hugh-Curtis syndrome. Acta Med Okayama, 2006; 60(5): 289-94.

110. Taylor-Robinson D. Mycoplasma genitalium-an update. Int J STD AIDS, 2002; 13: 145-51.

111. Tebb KP, Paukku MH, Pai-Dhungat MR, Gyamfi AA, Shafer MA. Home STI testing: the adolescent female's opinion. J Adolesc Health, 2004; 35(6): 462-7.

112. Thomas K, Coughlin L, Mannion PT, Haddad NG. The value of Chlamydia trachomatis antibody testing as part of routine infertility investigations. Hum Reprod 2000 May; 15(5): 1079-82.

113. Tiitinen A, Surcel H, Halttunen, et al. Chlamydia trachomatis and chlamydial heat shock protein 60 -specific antibody and cell-mediated responses predict tubal factor infertility. Hum Reprod, 2006; 21 (6): 1533-8.

114. Tuuminen T, Palomaki P, Paavonen J. The use of serologic test for the diagnosis of chlamydial infections. J Microbiol Methods 2000 Nov; 42(3): 26579.

115. US Preventive Services Task Force. Screening for Chlamydial Infection: Recommendations and Rationale. Am J Prev Med, 2001; 20 (3S): 90.

116. Van Bergen JEAM, Spaargaren J, Götz HM, et al. Population prevalence of Chlamydia trachomatis and Neisseria gonorrhoeae in the Netherlands. Should asyntomatic persons be tested during population-based Chlamydia screening also for gonorrhoeae or only if Chlamydial infection I found? BMC Infectious Diseases, 2006; 6: 42.

117. Van de Laar MJ. The emergence of LGV in Western Europe: what do we know, what can we do? Euro Surveill, 2006; 20: 11(9).

118. Veenemans LM, van der Linden PJ. The value of Chlamydia trachomatis antibody testing in predicting tubal factor infertility. Hum Reprod; 17(3): 6958.

119. Veldhuijzen IK, MSc, Van Bergen JEAM, MD, et al.: Reinfections, persistent infections and new infections after population screening for Chlamydia trachomatis infection in the Netherlands. Sex Transm Dis, 2005; 32(10): 599-604.

120. Verhoeven V, Avonts D, Meheus A, et al. Chlamydial infection: an accurate model for opportunistic screening in general practice. Sex Transm Infect, 2003; 79: 313-317.

121. Wallin KL, Wiklund F, Luostarinen T, et al. A population-based prospective study of Chlamydia trachomatis infection and cervical carcinoma. Int J Cancer, 2002; 101(4): 371-4.

122. Wang SP, Grayston JT. Immunologic relationship between genital TRIC, lymphogranuloma venereum, and related organisms in a new microtiter indirect immunofluorescence test. Am J Ophthalmol. 1970 Sep; 70(3): 367-74.

123. Ward AM, Rogers JH, Estcourt CS. Chlamydia trachomatis infection mimicking testicular malignancy in a young man, Sex Transm Infect, 1999; 75: 270.

124. Warner L, PHP, MPH, Stone KM, et al.: Condom use and risk of Gonorrhea and Chlamydia: a sistematic Review of design and measurement factors assessed in epidemiologic Studies. Sex Transm Dis, 2006; 33(1): 36-51.

125. Weidner W, Diemer Th, Huwe P. The role of Chlamydia in prostates. Int J Antimicr Agents, 2002; 19: 466-70

126. Weidner W, Schiefer HG, Krauss H, et al. Chronic prostatitis, a thought search for etiologically involved microrganism in 1461 patients. Infection, 1991; 
19 (13): 119-25.

127. Welte R, Mardh A. A cost-effectiveness of screening programs for Chlamydia trachomatis: a populationbased dynamic approach. Sex Transm Dis, 2000; 27 (9): 518-29.

128. Westrom L, Mardh P-A. Chlamydial salpingitis. British Medical Bulletin, 1983; 39: 145-50.

129. WHO: Global prevalence and incidence of selected curable sexually transmetted infections - overview estimated, World Health Organization, Geneva, 2001.

130. Wu S, Shen L, Liu G. Study on vertical transmission of Chlamydia trachomatis using PCR and DNA sequencing. Chinese Medical Journal (English), 1999; 112 (5): 396-9.

131. Zenilman JM. Chlamydia and cervical cancer: a real association? JAMA, 2001; 258: 81-3.

132. Zrodowska-Stefanow B, Ostaszewska I, et al. Role of chlamydia in epididymitis. Part I: Direct and serolig diagnosis. Med Sci Monit, 2000; 6(6): 1113-8. 